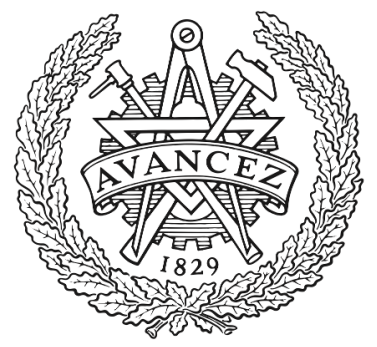

CHALMERS

UNIVERSITY OF TECHNOLOGY

\title{
Behavioural ambidexterity: effects on individual well-being and high performance work in academia
}

Downloaded from: https://research.chalmers.se, 2023-04-26 07:17 UTC

Citation for the original published paper (version of record):

Raidén, A., Räisänen, C., Kinman, G. (2020). Behavioural ambidexterity: effects on individual well-being and high performance work in academia. Journal of Further and Higher Education, 44(4): 568-582.

http://dx.doi.org/10.1080/0309877X.2019.1596232

N.B. When citing this work, cite the original published paper. 


\section{Behavioural ambidexterity: effects on individual well-being and high performance work in academia}

\section{Ani Raiden, Christine Räisänen \& Gail Kinman}

To cite this article: Ani Raiden, Christine Räisänen \& Gail Kinman (2019): Behavioural ambidexterity: effects on individual well-being and high performance work in academia, Journal of Further and Higher Education, DOI: 10.1080/0309877X.2019.1596232

To link to this article: https://doi.org/10.1080/0309877X.2019.1596232

曲 Published online: 08 Apr 2019.

Submit your article to this journal $₫$

Џ Article views: 100

Q View related articles ¿

View Crossmark data $\asymp$ 


\title{
Behavioural ambidexterity: effects on individual well-being and high performance work in academia
}

\author{
Ani Raiden (1D) ${ }^{a}$, Christine Räisänen ${ }^{\mathrm{b}}$ and Gail Kinman ${ }^{\mathrm{c}}$
}

${ }^{a}$ Nottingham Business School, Nottingham Trent University, Nottingham, UK; ' ${ }^{\circ}$ Construction Management, Chalmers University of Technology, Göteborg, Sweden; 'Research Centre for Applied Psychology, University of Bedfordshire, Luton, UK

\begin{abstract}
Academic work demands behavioural ambidexterity: the ability to simultaneously demonstrate exploration (creativity in research and/or in innovative teaching and learning practice) and exploitation (compliance with quality assurance). However, little is known about the effects of behavioural ambidexterity on the well-being of individual employees. We explore the experiences of men working in academic roles at universities in Sweden and the UK. More specifically, we examine the relations between behavioural ambidexterity and perceptions of well-being using an interpretative approach based on narrative analysis. Despite societal differences between Sweden and the UK, academics in both countries felt ill-equipped to fulfil the demands for ambidexterity. This resulted in mixed performance outcomes with serious implications for well-being. We identify and discuss the influence of personal circumstances and the role of agency in work design as two key antecedents of positive well-being outcomes.
\end{abstract}

\section{ARTICLE HISTORY}

Received 28 February 2018

Accepted 12 March 2019

\section{KEYWORDS}

behavioural ambidexterity; performance; well-being; agency

\section{Introduction}

Trade-offs are an integral feature of organisational life and individuals' experiences of work. Knowledge-based professional work is particularly demanding, given varied job tasks, fuzzy boundaries and high autonomy, but it is also rewarding and self-fulfilling. Academia is one sector in which intrinsic motivation to 'do well' typically underpins commitment to work, where job involvement is high and where self-management of 'protean careers' and academic freedom contribute to a profound interest in and attention to work (Enders and Kaulisch 2006; Kinman and Jones 2008a). Conversely, as academic institutions adopt new transparency measures and quality-assurance (QA) schemes, the work of academics has become subject to growing scrutiny and is increasingly constrained by bureaucratic processes (Kinman 2014; Yli-Joki 2013).

A conflict between ensuing compliance and inspiring creativity, then, arises when organisations seek to adopt behavioural ambidexterity, i.e the ability to simultaneously demonstrate exploitation (compliance) and exploration (creativity) across a business unit (Gibson and Birkinshaw 2004, 209). Interest in the performance outcomes of behavioural ambidexterity is growing (see Ahammad et al. 2015; Patel, Messersmith, and Lepak 2013), but little is known about its effects on individual well-being. We explore the experiences of 14 men working in academic roles at universities in Sweden and the UK, focusing on: 
(1) How they experience their work.

(2) How they perceive their well-being.

(3) How behavioural ambidexterity helps and/or hinders the relationship between work design and well-being.

The influence of personal circumstances and the role of agency in work design are key antecedents of positive well-being. Our contribution adds in-depth qualitative insights to complement largely quantitative evidence that has been previously generated (see Wood et al. 2012). Focusing on men means that we are able to expand knowledge in a space that has not been extensively studied: a considerable body of research has documented women's (especially mothers') struggles to navigate the demands of the contemporary workplace (Chang, Chin, and Ye 2014; Kinman 2016). Research on men and fathers is only recently emerging (see, for example, Gatrell et al. 2015; McDonald and Jeanes 2012). This imbalance drove our sampling strategy: we specifically wanted to speak with respondents who self-identified as 'new men' (Hearn 1999) or 'working fathers' (Ranson 2012), concepts that refer to men who value personal well-being and seek a work-life balance.

It is generally understood that, in Sweden, gender equality is further advanced concerning women's workplace participation and men's involvement with family. Culturally, Swedish society values quality of life, whereas in the UK more traditional gender roles and a long-hours work culture seem to prevail (Gregory and Milner 2011; van der Lippe, Jager, and Kops 2006, 307) within an individualist and masculine value system (Taras, Steel, and Kirkman 2011, 191). ${ }^{1}$ Moreover, 'new public management' has changed the landscape of academia in both countries (Barry, Berg, and Chandler 2006; Lorenz 2012), transforming work practices in higher education (HE) and giving rise to conflicting demands and pressures (Ambos et al. 2008; Menzies and Newson 2008). This seems to be taking its toll on its workers as their well-being has diminished over time (Kinman 2014). For men who wish to work flexibly, particularly for the purposes of child-care, there is the added pressure of being viewed negatively by colleagues and managers (women as well as men) and being deemed less motivated and less deserving of promotion and salary increases (Kelliher and Anderson 2008; Rudman and Mescher 2013). Nonetheless, how men cope with work, family and life situations remains an under-researched area.

\section{Conceptual framework: behavioural ambidexterity-performance-well-being}

Our conceptual framework draws together behavioural ambidexterity, performance and well-being, as shown in Figure 1.

In organisational research, ambidexterity refers to an organisation's ability and desire to simultaneously pursue two different, often conflicting, aims: exploration and exploitation (see Birkinshaw and Gupta 2013; Simsek 2009). There are three forms of ambidexterity in organisations: temporal, structural and behavioural (Gibson and Birkinshaw 2004). In temporal ambidexterity, exploitation and exploration are sequential depending on organisational and environmental requirements (Swart et al. 2016). Structural ambidexterity utilises 'dual structures', where certain business units concentrate on exploitation while others focus on exploration (Gibson and Birkinshaw 2004). Behavioural ambidexterity is the capacity to simultaneously demonstrate exploitation and exploration across a business unit. It encompasses manifold ways in which organisations manage the tensions inherent in doing two different things at the same time (Birkinshaw and Gupta 2013). Within academia, behavioural ambidexterity is predicated on its strong generative interrelationship between research, teaching and administration; these imbricated strains are dependent on an effective balance of compliance and creativity.

Behavioural ambidexterity has become a popular concept not only because it is versatile, but also because it is closely associated with notions of employee engagement and high-performance work systems (Patel, Messersmith, and Lepak 2013). Research tends to favour the performative potential. Although employee well-being is an important concern for contemporary management practice, as yet, it has not been investigated within an ambidexterity framework. We query the 


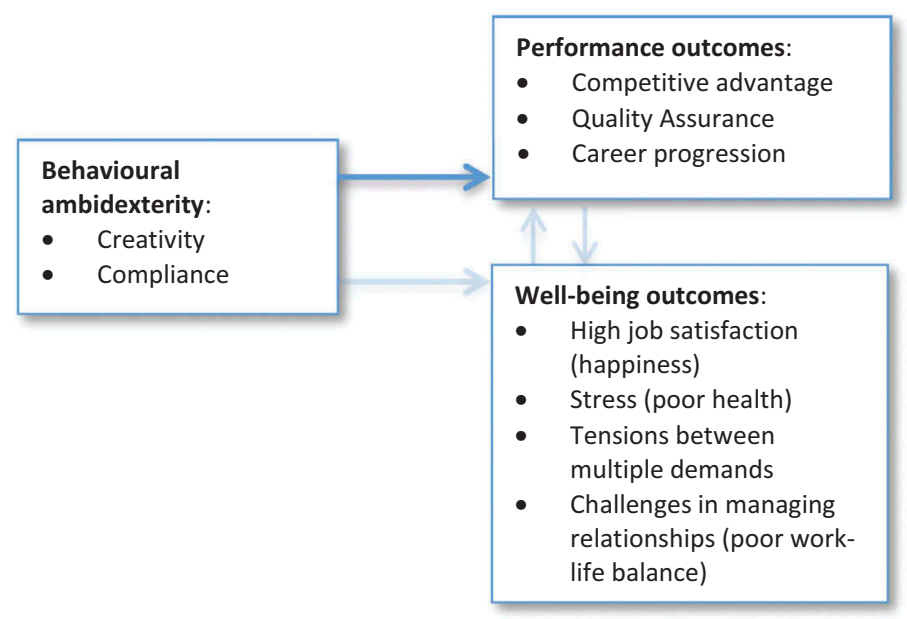

Figure 1. Conceptual framework.

Source: After Gibson and Birkinshaw (2004), Simsek (2009), van de Voorde, Paauwe, and van Veldhoven (2012) and Patel, Messersmith, and Lepak (2013).

relations between behavioural ambidexterity and performance and well-being in academia since jobs that combine variety with autonomy and flexibility tend to produce positive performance outcomes but varied well-being outcomes (Humphrey, Nahrgang, and Morgeson 2007; Oldham and Hackman 2010).

The anticipated performance outcomes include research income, high quality publications, realworld impact, innovative teaching and learning, student support, as well as timely and accurate administration of procedures, the aggregation of which ensures the career progression of individual employees. Achievement of such performance outcomes collectively leads to organisational competitive advantage (league table performance, Research Excellence Framework (REF) ${ }^{2}$ status, student intake, research grant income, etc.) and QA status.

The well-being outcomes in the framework derive from a holistic definition based on healthcare, philosophy, psychology and sociology literatures, which encompass three core dimensions of wellbeing: psychological (happiness), physical (health) and social (relationships) (Grant, Christianson, and Price 2007, 52). Happiness refers to the psychological well-being of employees; key issues are satisfaction with work and life in general, with focus being placed on subjective experiences and functioning at work (Grant, Christianson, and Price 2007), and commitment to the organisation (van de Voorde, Paauwe, and van Veldhoven 2012). Health refers to the physical and psychological well-being of employees in terms of experiences of strain or work-related stress and outcomes such as cardiovascular disease, hypertension, sleeping problems, mental health issues and workplace accidents (Grant, Christianson, and Price 2007; van de Voorde, Paauwe, and van Veldhoven 2012). Relationships are a recent addition to considerations of employee well-being (Grant, Christianson, and Price 2007; van de Voorde, Paauwe, and van Veldhoven 2012), encompassing the interactions and quality of relationships between people, both within the workplace and in their personal life.

Extant literature suggests that academics enjoy high job satisfaction (happiness) but suffer from stress (poor health) and experience work-life balance challenges (poor relationships) (Bentley et al. 2013; Kinman 2014). The high autonomy that many academics experience may also enable intensification whereby increased flexibility can further threaten work-life balance and recovery processes rather than facilitate them (Kinman and Jones 2008b).

A strong connection between performance and well-being has been established (see, for example, Edgar et al. 2015). This supports the view that a 'mutual gains' perspective facilitates the achievement of positive organisational (performance) and individual (well-being) outcomes 
(van de Voorde, Paauwe, and van Veldhoven 2012). Here, the links between management practice and happiness, health and relationships are generally assumed to be positive in that managers focus on building a two-way exchange between organisational support and employee trust and commitment. Alternatively, the 'conflicting outcomes' perspective posits that managerial practices have either no or a negative effect on well-being (Grant, Christianson, and Price 2007; van de Voorde, Paauwe, and van Veldhoven 2012, 392-393). This acknowledges that the type of management practices that produce high performance (organisational focus) are probably different to those that enhance employee well-being (employee focus).

\section{Research approach}

Research on ambidexterity has mainly taken the organisation as the unit of analysis (Birkinshaw and Gupta 2013, 291; Swart et al. 2016); our contribution is at the level of the individual. As we wished to gain in-depth insights into how academic men perceived and reasoned around their work and its associations with performance and wellbeing, a qualitative research approach was appropriate. A comparative study was designed, based on life-story interviews and narrative analysis. Research ethics approval was granted by Nottingham Trent University, UK.

Interviews were conducted with 14 men (seven each from Sweden and the UK) from constructionrelated departments at universities in the two countries. Assistant professors (1), lecturers (4), senior lecturers (4) and professors (5), aged from their mid thirties to their early sixties, were represented (Table 1). Most respondents had full-time posts; four worked part time in academia). All respondents were married or in a long-term relationship, and all but one had children between 18 months to 32 years. The interviews, lasting around one hour, were recorded and transcribed verbatim.

We employed a purposive informant-sampling strategy, and tried to match categories and ages of respondents in the two countries. It was important to access views from 'new men' employed at different hierarchical levels in academia. The lived experience of each interviewee was considered a situated, specific life story. We wished to capture individual contextual circumstances, past and present, and how individuals coped with them, both practically and affectively. Capturing their affective attitudes relating to happiness, health and relationships was especially important in providing insight into their well-being.

We make use of characterisations (Barry, Berg, and Chandler 2006) in contextualising our discussion, and draw on the characteristics of the interviewees to describe their experiences of ambidexterity and

Table 1. Participant profile.

\begin{tabular}{|c|c|c|c|c|c|}
\hline Country & Job role & Age & Family & $\begin{array}{l}\text { Contract of } \\
\text { employment }\end{array}$ & Identifier \\
\hline UK & Lecturer & $45-49$ & Wife 2 children (school age) & 0.2 & Lecturer 1, UK \\
\hline UK & Lecturer & $50-54$ & Wife 1 child (pre-school) & 0.6 & Lecturer 2, UK \\
\hline UK & Lecturer & $40-44$ & Wife 2 children (school age) & Full time & Lecturer 3, UK \\
\hline UK & Senior Lecturer & $40-44$ & Wife 2 children (pre-school) & Full time & Senior Lecturer 1, UK \\
\hline UK & Senior Lecturer & $55-59$ & $\begin{array}{l}\text { Wife } 3 \text { children (pre-school } \\
\text { and teenage) }\end{array}$ & Full time & Senior Lecturer 2, UK \\
\hline UK & Professor & $40-44$ & Partner & Full time & Professor 1, UK \\
\hline UK & Professor & $40-44$ & Partner 2 children (school age) & Full time & Professor 2, UK \\
\hline Sweden & Lecturer & $35-39$ & Wife 2 children (school age) & $\begin{array}{c}\text { Full time (now outside } \\
\text { of academia) }\end{array}$ & Lecturer, Sweden \\
\hline Sweden & Assistant Professor & $35-39$ & Wife 2 children (pre-school) & Full time & $\begin{array}{l}\text { Assistant Professor, } \\
\text { Sweden }\end{array}$ \\
\hline Sweden & Associate Professor & $50-54$ & Wife 3 children (grown up) & 0.5 & $\begin{array}{l}\text { Associate Professor 1, } \\
\text { Sweden }\end{array}$ \\
\hline Sweden & Associate Professor & $45-49$ & $\begin{array}{l}\text { Wife } 3 \text { children (teenage and } \\
\text { grown up) }\end{array}$ & Full time & $\begin{array}{l}\text { Associate Professor 2, } \\
\text { Sweden }\end{array}$ \\
\hline Sweden & Professor & $50-54$ & Wife 2 children (teenage) & Full time & Professor 1, Sweden \\
\hline Sweden & Professor & $50-54$ & Wife 3 children (grown up) & 0.7 & Professor 2, Sweden \\
\hline Sweden & Professor & $60-64$ & Wife 1 child (grown up) & Full time & Professor 3, Sweden \\
\hline
\end{tabular}


related performance and well-being outcomes. However, we avoided mentioning analytical terminology, such as 'ambidexterity' or 'happiness' in our prompts. Narrative analysis (Polkinhorne 1995) was applied to the data to identify and sort the plots and themes in the life-stories. Both separate and collaborative reflexive close-readings of the transcripts strengthened our interpretations. ${ }^{3}$

Philosophically, phenomenology underpins our research. We used descriptive analysis of the experiences and perceptions expressed by the participants in relation to behavioural ambidexterity and well-being. We queried the intentionality of their life stories and encouraged them to reflect upon their awareness of self and other persons relevant to their experiences. Exploring the conditions of possibility, contexts both within and outside work, was of particular interest and helped us develop insights into the multiple and parallel constraints and allowances the respondents highlighted.

\section{Research findings}

In the following sections, we initially consider behavioural ambidexterity and subsequently discuss the well-being implications and present three characterisations that emerged to showcase the ways in which respondents experienced ambidexterity and well-being. Finally, we develop the comparative analysis (Sweden-UK) and consider whether the mutual-gains perspective or the conflicting outcomes perspective more closely aligns with the respondents' experiences.

\section{Behavioural ambidexterity}

A central theme in the respondents' accounts was 'multiple roles inherent in academic work', with many referring to 'the usual mix of teaching, admin and research' (Senior Lecturer 1, UK). However, the relative importance of these elements varied considerably between people and institutions, and depended on their career stage. Those lower in the organisational hierarchy indicated a predominance of teaching and administrative work whereas professorial work mainly focused on research publications and grant income.

Our respondents at all levels and in both countries alluded to the challenges of career progression. Advancement depends on demonstrating competence in each role (teaching, administration and research), although workloads were not evenly distributed between different levels of the hierarchy. Managing performance standards and quality control was fraught with tension. On the one hand, we evidenced a strong intrinsic motivation to do well and deliver the best work they could, for example employing innovative, practical learning activities. On the other hand, respondents in the UK especially reported that centralised timetabling eroded flexibility in managing contact hours, and student feedback initiatives could police the quality of the feedback. Organisational discourse was increasingly concerned with QA, but our respondents perceived a gradual weakening of academic quality in spite of the increased monitoring. Lecturers felt they were deliverers of a standardised product rather than providers and generators of knowledge. Wellbeing concerns and a sense of de-professionalisation were also evident.

Flexibility was the benefit that was most appreciated by all respondents. It offered opportunities to make important life choices and balance competing demands: for example, to spend time with family during office hours and work in the evenings. While all respondents appreciated the flexible scheduling of academic work, only two discussed it in wholly positive terms. Four respondents from each country said they work long hours. Professor 2 and Senior Lecturer 2 from the UK estimated that they worked 65-70 hours in an average week, and 12-hour working days were not uncommon. In Sweden, respondents reported working an average of 55 hours. Rather than being an organisational support mechanism, working-time flexibility tended to tighten the bind between the academics and their work. One respondent each from Sweden and the UK also reported feeling unable to engage with the formal care resources provided by their employer (such as counselling 
during stressful times) because of the stigma associated with the uptake of such initiatives, especially for men (Cech and Blair-Loy 2014; Kinman and McDowall 2017).

Despite the challenges of occupying 'multiple roles' and ensuring career advancement, many respondents working full time spoke positively about the possibilities offered to pursue their academic ambitions, for example research goals and teaching aspirations. According to UK Professor 2, academia is the only workplace today where 'one can become whatever one wants to be'. One Swedish respondent considered his work to be a hobby as well as a job. Reflecting the findings of previous studies in academia (Kinman and Jones 2008a), these respondents' social identities were closely tied to their work.

Erosion of agency in work design emerged as an important theme. Work demands and the nature of work were seen to evolve according to external and internal pressures, and the balance kept shifting between autonomy and freedom, and management control and structures designed to ensure accountability. Exploration was central to the respondents' accounts of work: the creative elements that make academic work 'professional and knowledge-based'. However, this was not always available to those at the lower levels, in line with Swart et al. $(2016,13)$, who associated the level of seniority with ambidexterity in professional service. In academia, research work was deemed the most desirable and strived-for element of the job, which many struggled to accommodate in their schedules (see also Barry, Berg, and Chandler 2006). Thus, they had to resort to the compliance mode (exploitation), which then filled most of their role. This is especially true for lecturers and associate professors.

Careful time management and prioritisation of tasks and activities emerged as successful strategies for balancing different demands. UK Professor 2 discussed prioritising commitments and involvement, and delegating certain work tasks to junior colleagues. The rationale here was that these tasks served as useful staff-development activities, offering opportunities to participate in, for example, committee work (exploitation), while the more senior colleague frees up time for strategic exploration. Planning work ahead of time was considered essential to achieving a mix of exploration and exploitation, akin to Litrico and Lee's (2008) orchestrated cooperation.

Another successful strategy was structural, based on the rolling appointment of senior leaders for a fixed period. Professor 2 from the UK reflected on how his appointment to a demanding position for three years was manageable because it was time-bound. He focused his efforts on the university's strategic priorities (exploration at the organisational level) at a temporary cost to his personal development (exploration at the person/role level). This illuminates the possibilities for academics to demonstrate exploration along temporal lines as well as behavioural ambidexterity.

\section{Well-being}

One of our respondents talked about his work in academia in very positive terms:

\footnotetext{
I feel, in my job, very privileged. I consider that to be a very satisfying part of my life ... I enjoy sitting on university committees, and it's nice that the Vice Chancellor knows who I am ... [but] had I not done that and just carried on being a mainstream academic, I think I would have been just as satisfied as I am now. No other job I'd rather do than the job I do, and it's nice to be able to say that. (Professor 2, UK)
}

This professor has developed a successful career in academia through hard work and long hours. Although we probed about his life beyond work, he invariably returned to his work circumstances. He may well represent the 'ideal' worker who is committed to what he does, and from whom an organisation can only ever expect to gain positive outcomes. The relationship between Professor 2 in the UK and his employer is mutually beneficial as the synergy in academic entrepreneurship at the level of the organisation and the individual results in job satisfaction (a measure of happiness) (Grimaldi et al. 2011, 1050).

One of our Swedish respondents also talked about his work situation in such positive terms: 
The academic world is a great place for self-development, developing knowledge, and with many intelligent and nice people to interact with, both colleagues and students, so I enjoy the environment. (Associate Professor 1, Sweden)

Notably, these two academics align themselves with the general nature of the work and the environment within which it is done. Others highlighted individual aspects of their work as particularly satisfying, for example travel and the opportunity to mix with academic, industry and political decision-makers. Academics in managerial roles, in both countries, particularly enjoyed the opportunities to wield influence at a strategic and political level and to develop their research profiles by strengthening their niches through international collaboration and networking. These respondents felt empowered by the increased scope for entrepreneurial activity within their role. One school of thought argues that universities should proactively develop academic entrepreneurship and provide incentives for their personnel to devote time and energy to such activities (Grimaldi et al. 2011). The following professor expressed a markedly achievement-oriented take on job satisfaction:

Making sure I achieve is important ... I like to achieve personally ... There's always a need to push things forward and to try and make things that little bit more comfortable, otherwise you'd lose your drive. (Professor 1, UK)

Other respondents were more critical of their work circumstances, and it was difficult to extract anything but a lukewarm, neutral or, in some instances, an overtly negative response. Their job satisfaction was reduced by feelings of under-achieving and an inability to do a good job in any sphere, which in turn eroded their self-confidence.

As a result, some worrying symptoms of ill-health thought to be related to the job were evident: psoriasis, stress, heart problems and 'nervousness'. These complaints were articulated by 4 out of the 14 respondents, 2 each from Sweden and the UK. Additionally, Professor 3, Sweden, mentioned that 'his physical health was good - his mental health was bad'. He expressed his frustration, verbally and through body language, towards the university and his manager. Given the small sample size, five is a disproportionately high number of respondents to report severe health concerns. As half of the respondents (three Swedish and five British) disclosed a desire to increase their involvement in sports activities, it was not only their current health that was of concern, but also possible problems due to reduced physical activity. These eight respondents had been active sportsmen in younger years, and expressed nostalgia for a part of their lives that they have had to abandon due to lack of time. Two respondents, however, used sports as a de-stressor: cycling to and from work provided a liminal space and time for thinking, or not thinking.

Managing relationship-related well-being outcomes seemed mixed. All the men mentioned how their careers had been, and often still were, enabled by understanding partners or wives. In all narratives, the wife/partner was depicted as the one who 'reshuffled', 'reduced' or 'gave up' job arrangements and plans for the men's career and/or needs of children. Interestingly, most respondents noted that these accommodations were jointly negotiated by both partners. Only Associate Professor 1 from Sweden likened his relationship with his partner to that of a patient-nurse, and Senior Lecturer 2 from the UK admitted that his wife felt undervalued because he always put work first.

Regarding involvement with family in general, the men's accounts dealt with activities such as the school run, bath time, sports and holidays. One UK-based respondent noted how family commitments served as a way of mitigating overwork:

Those things that you have to do are often an excuse to say, 'I'm stopping work now, because I've got to pick up the kids from school'... So, actually, contact with the family puts a limit on the 'creep'. (Lecturer 1, UK)

Only one respondent (Associate Professor 2, Sweden) had a family storyline of shared caring and decision making in the family unit. This indicates that, for this small sample of academics, work takes up most of their time and concern.

In line with Litrico and Lee's (2008) research, we found that behavioural ambidexterity was a requirement both within work and out of work activities. However, there was an imbalance of exploration and exploitation outside the work context. While some exploration (flexibility) on the 
part of academics supported family responsibilities, family/spouses predominantly demonstrated exploration in seeking to accommodate the needs of their academic partner. Thus, the men in our sample align with the 'solo performance' or 'organic fluid adjustment' patterns that Litrico and Lee $(2008,1009)$ presented. These patterns suffer from a lack of boundaries and the segmentation of different contexts (e.g. work and life). Individuals often feel a strong need to continually adapt to changing circumstances at work and exhibit high degree of exploration.

'Orchestrated cooperation' (Litrico and Lee 2008, 1011) offers a better balance of exploration and exploitation, whereby flexibility is recognised as a necessity, but managed with careful planning and structure in order to gain benefits from exploitation (e.g. routines and time tracking). Indeed, two of our respondents (UK Senior Lecturer 1 and Professor 2) referred to setting boundaries and establishing routines that helped balance work commitments and time with family. Friday night was designated 'e-mail free', and holidays were 'sacred' time away from work.

Concerning relationships with friends, the respondents expressed a lack of social contact in terms of temporal distance (not spending time together) and relational distance (lack of intensity in interaction). Many acknowledged the negative implications that striving to manage relationships and achieve a work-life balance had for their job satisfaction.

\section{Discussion and conclusion}

\section{Characterisations}

We discerned three identity-clusters that shaped the characterisations emerging from our analysis: high performers, core workers and the disgruntled.

The first cluster, high performers, comprises high achievers who had mixed well-being outcomes. For example, Professors 1 and 2 in the UK engaged in more exploration at work and benefitted from exploitation at home; consequently, their work performance and job satisfaction were high. They reported no specific health concerns, but suffered from poor relationships at home. Professor 2 and the Lecturer, Sweden, also exhibited characteristics relevant to this cluster. Professor 2 engaged in more exploration at work, but presented a balance between exploration and exploitation at home. His work performance and job satisfaction were high, but he had suffered poor health in the form of burnout. He described his relationships as satisfactory. While this lecturer also engaged in more exploration at work and presented a balance of exploration and exploitation at home with high performance and job satisfaction, his health and relationships were both poor. However, in spite of their overall job satisfaction, academics in this cluster acknowledged the negative implications for well-being, with their health and relationships most likely to suffer. High performers benefitted from exploration at work and the flexibility offered them by supportive spouses at home or from alternating the support when the need arises.

Focus on work and achievement orientation point to gendered identify work that serves a dual purpose: on the one hand, in male-dominated occupations (such as construction) and work-life boundary-spanning academic work many networking opportunities necessary for securing good job prospects and career advancement reinforce the traditional male role model - that of a breadwinner - and thus tightly bind the academics to their work. On the other hand, 'male bonding' and 'brotherly competition' (after Vehviläinen, Vuolanto, and Ylijoki 2010) amongst the networks produce feelings of belonging and a sense of achievement, which shape job satisfaction.

The second cluster, core workers, comprises academics who tended to use exploitation combined with good performance and well-being outcomes. The most positive experience within this cluster was evidenced by UK Senior Lecturer 1 . He achieved some balance between exploration and exploitation at work and at home, but we noted that he sometimes used more exploitation in the context of work. He performed well at work and reported good well-being outcomes. Associate Professor 1 in Sweden and Lecturer 3 in the UK reported using exploitation at work and at home. Their performance at work was 
good and their well-being outcomes were mixed: poor job satisfaction, minor health concerns and satisfactory relationships. UK Lecturers 1 and 2 used exploitation at work and engaged in exploration at home. These part-time lecturers were employed in teaching-only roles, and may have felt their contribution was limited compared with that of their full-time colleagues given the prestige of the organisational narrative on research-related work. Thus, their performance at work tended to be average and they experienced poor job satisfaction with the academic part of their work, but reported good health and relationships. Associate Professor 2, Sweden, juggled work and relationships, both of which could be improved, but he identified no overt ill-health problems and used exploitation strategically to achieve his aims.

While the high performers used exploration, core workers used exploitation. Interestingly, they exhibited the most beneficial well-being outcomes in terms of health and relationships, but this tended to be at the expense of meaningful and fulfilling work engagement. A relationship between exploration and job satisfaction, on the one hand, and exploitation and good health and relationships, on the other, is emerging.

The third cluster comprises the disgruntled: those who reported poor well-being outcomes, regardless of whether they used exploration or exploitation. Professors 1 and 3, Sweden, used more exploration at work, and mostly exploitation with some exploration at home. Their performance at work did not achieve their ambitions or their aims, their job satisfaction and health were poor, but they had good relationship outcomes. UK Senior Lecturer 2 and the Assistant Professor in Sweden tended to use exploitation at work. The Assistant Professor was struggling to fulfil all his teaching and supervision tasks in lightof the high goals he had set himself and felt he was failing. He also reported poor well-being outcomes. The academics in this cluster had no sense of job satisfaction, suffered from poor work-related health and experienced poor relationships. This cluster suggests that the relationship between exploitation and good health and relationships does not hold.

\section{Comparison: Sweden-UK}

Subtle differences emerged in the accounts of respondents from Sweden and the UK. The respondents talked about their experiences of managing relationships in gendered terms: many UK men had stayat-home partners, which they tended to rationalise as financially beneficial and advantageous for the children. There is little evidence of reflection about what this situation meant for their partner. The Swedish academics depicted a similar division of labour, but with an interesting difference in discourse and affect. Typically, they were more inclusive and empathetic to their partners' perspectives. Many Swedish men mentioned 'feeling guilty' about the sacrifices their partners had made to enable their success. Moreover, Swedish respondents were candid about the negative effects of work intensification on their health and well-being, commenting on their inability to adequately fulfil the many demands of their job roles. British respondents tended to attribute their challenges to management systems and pressures, and expressed frustration and anger towards 'the top', thereby externalising their problems. They had to be prompted to speak of family and work-life balance. These differences may be explained by the feminine national culture associated with Sweden, where 'emotional gender roles overlap: both men and women are supposed to be modest, tender, and concerned with the quality of life' (Hofstede, Hofstede, and Minkov 2010, 140-144). Overt achievement orientation is more pronounced in the UK, and men appear reluctant to show vulnerability by disclosing possible weaknesses. It is important for future research to gain deeper understanding of how 'new' men, who are situated in different national and organisational cultures, respond to the stigma associated with weakness and the effects on their well-being, job performance and advancement, as well as their satisfaction with personal relationships.

\section{Theoretical implications}

Our study responds to recent calls for research into ambidexterity at the level of the individual and extends existing knowledge on behavioural ambidexterity by revealing patterns and 
connections regarding academic work and well-being outcomes. The high-performing academics used exploration at work, underpinned by a strong drive and work orientation, and benefitted from supportive arrangements at home. This combination was critical to their success. All the other academics felt ill-equipped to fulfil the demands for ambidexterity imposed on them, which threatened their central academic contributions: creativity and intellectual input. They often used exploitation at work, especially in their teaching activities. This compromised their ability to deliver high-performance outcomes due to a devaluing of such activities compared with research-related pursuits. Neither their employers nor the respondents appeared to personally benefit from the focus on exploitation. The mixed well-being outcomes found are cause for concern and deserve attention.

We deepen the understanding of behavioural ambidexterity by linking individual circumstances and work context as key antecedents of behavioural ambidexterity, highlighting the interrelatedness of performance and well-being outcomes. We built on Litrico and Lee's (2008) work on balancing exploration and exploitation in alternative work arrangements, suggesting there are patterns that allow exploration and exploitation to mix or become counterbalanced; they need not always compete (1016). Since this balance is a fragile equilibrium and stressful to manage (Litrico and Lee 2008), we argue that behavioural ambidexterity cannot be considered solely in the organisational context (and in relationship performance outcomes). We therefore added 'personal circumstances' to our conceptual framework. A more inclusive and balanced framework thus emerges, one that acknowledges the centrality of the employee in achieving behavioural ambidexterity.

Engaging in ambidexterity varied according to the respondents' positions within academia. We observed a continuous pull and push within each individual between personal desires, institutional demands and family domains; daily tensions arise that crave mental and physical energy and effort to resolve. The more senior and entrepreneurial the respondents, the more they tended to use exploration. This is not surprising; however, what prior research has not identified is that exploration builds on judgement and experience as well as resources and support. Academics at lower levels of the hierarchy typically used exploitative behaviours; partly because these were safer and enabled them to learn 'the ropes' and partly because of the way their work was allocated. These patterns concur with research findings on professional service firms (see Swart et al. 2016). What complicates matters for academics is that recruitment and selection panels demand evidence of excellence across the domains of research, teaching, entrepreneurship and administration.

In line with Clarke, Knights, and Jarvis (2012), we also found that academics tended to comply with the demands made upon them, but their love for the work is being eroded by instrumental and administrative pressure. Thus, it is the conflicting outcomes perspective that more closely aligns with our respondents' experiences of behavioural ambidexterity and well-being. While it is clear that ambidexterity is inherent in the way work is organised in academia - and in theory it offers a variety of tasks ensuring good performance outcomes - the well-being implications seem largely negative. Creativity and intellectual contribution, central to success for both individual and organisation, suffer. This is of concern as intrinsic job satisfaction has traditionally counterbalanced the great effort required of academics and dissatisfaction with the more extrinsic aspects of the role such as terms and conditions of employment and pay (Kinman 2016).

At the same time, behavioural ambidexterity feeds 'greedy jobs' and demands more time and resources away from the home. If men cannot access organisational support and/or take advantage of flexibility at work in a way that helps work-life balance, rather than enables work intensification, then their ability to contribute to relationships and family is limited. This, in turn, reproduces women's position within the family as the primary caregiver and recasts 'new men' as breadwinners. 


\section{Implications for management practice}

We conclude that happiness tended to be an outcome of the respondents' accounts of success at work. They had made considerable sacrifices in prioritising work over recreational activities, which, in combination with the adverse effects of pressure at work, could have serious negative consequences for their well-being in all three domains: happiness, health and relationships. Family relationships mostly operated on a one-way support basis despite respondents having identified as 'new men'; partner/wife (and children) enabled the men to develop and maintain successful careers - often at the expense of family well-being.

These findings implicate management practice in two ways: first, academia has very effectively tapped into the workers' affective commitment, and these academics have a strong intrinsic desire to do well, which in turn reflects positively on their well-being. Yet, tensions were evident in their accounts of work, well-being and the relationship between the two. As Ashcraft and Trethewey (2004), among others, maintain, tensions are a regular feature of organisations, and academia is no exception. A prominent tension arises between the respondents' ability to design their work, i.e. their autonomy, versus the high managerial control they perceive. This tension, labelled the autonomy paradox, is common to knowledge workers: the more freedom employees have to design their work, the more they work, whereas the more constrained and controlled they feel by the organisation, the less effectively are they able to work (Michel 2011). This also reflects enabled intensification, whereas flexibility combined with high work demands and high job involvement typically results in more rather than less effort. In relation to ambidexterity, this effect manifests itself in individuals' perceived inability to focus on exploration and increasingly rely in exploitation. The more they use exploitative behaviour, the less autonomous they feel and the less inspiring becomes their work. This downward spiral can be debilitating for both the individual and the organisation, and is likely to lead to impaired performance and withdrawal behaviours.

In order to encourage commitment and intrinsic motivation, management practice should aim to enhance the creative aspects of ambidextrous work design, which would increase workers' feeling of empowerment. As Patel, Messersmith, and Lepak (2013), drawing on Gibson and Birkinshaw (2004), warn: behavioural ambidexterity is not created through organisational practices no matter how well-intentioned, but rather 'through the flexibility of allocating the time and attention of human resources toward exploration and exploitation' (1421). To be effective, behavioural ambidexterity should function on two levels: the organisation and the individual. What our data show is that academics perceive strong restrictions on their flexibility and have increasingly less time to fulfil their wide-ranging tasks, which limit the attention they are able to give to each task. The implications are that they then feel exploited, and their attention is therefore directed toward exploiting (making the best of the situation by doing what they must), rather than exploring to find new and better solutions. Professors, who have more control over their work design, may choose only to do tasks they consider to be legitimate, i.e. those tasks they consider align with their academic role and identity (Semmer et al. 2007).

At the core of the problem is loss of agency; lack of employee voice and autonomy. When an individual has a sense of control and influence in relation to their work - agency - their well-being tends to be more positive. Thus, a way of ensuring more positive well-being outcomes whilst benefitting from ambidexterity would involve managers and academics taking more active roles in work design that affect how work in academia should be accomplished. Higher-level changes in the legislative and normative environments are clearly fostering role identity modifications of university workers (Grimaldi et al. 2011), and these should be addressed collaboratively by academics and their managers. Jain, George, and Maltarich (2009) argue that establishing the microfoundations of academic entrepreneurship, for example, requires closer scrutiny of the university worker as a key contributor to this phenomenon. The importance of agency in health-specific wellbeing outcomes has long been recognised and is underpinned by recent longitudinal research that 
argues that job demands will be negatively related to mortality under conditions of high control (Gonzalez-Mulé and Cockburn 2016).

Finally, the relationship-related well-being outcomes reveal gendered implications of behavioural ambidexterity at work and home. We find that exploration beyond work is most commonly used by the female partners of the male academics in our study. This enables the men to focus on work and feeds their greedy jobs while making them physically and/or emotionally unavailable to fulfil roles in their personal life. It also maintains and reproduces traditional gender roles. Given the differences in societal values in Sweden and the UK, it is surprising to find such small differences in the sample. Universities and their human resources (HR) professionals and line managers play critical roles in promoting socially sustainable work design and thus contributing to achievement of gender equality over the long term.

\section{Limitations and future research directions}

Our intention has been to conduct an exploratory, in-depth study of the lived experiences of academic workers. However, we acknowledge that the sample size is limited and gender specific. We sought detailed answers to 'why' questions in an attempt to understand both causes and effects of individual perceptions of work and well-being. Further comparative studies, including countries in both Eastern and Western Europe, as well as in other continents, would provide interesting data. Moreover, studying larger samples, and including both male and female professionals as well as their partners, may reveal interesting insights and generate comparative data to allow researchers to either confirm that our findings are gender neutral (thus highlighting the organisational and structural issues) or confirm that men struggle to balance work and life/ relationship commitments in specific ways. Studying larger samples would also allow the mapping of further categories in relation to 'personal circumstances' - our respondents highlighted partner and family, social networks, interests and hobbies and personal development as the domains that were important to them. Different occupational groups may reveal different priorities. Moreover, it would be useful to investigate to what extent high performers have benefitted from training and development, allowing them to take advantage of the entrepreneurial opportunities open to them and/or to what extent it is the mind-set inherent in a person's value system and personality that influences their perception, performance and well-being. Finally, our focus in this study has been on the individual level. Researching managers' and HR professionals' perceptions of behavioural ambidexterity, work performance and well-being outcomes would provide a more holistic picture and lead to deeper understanding of the complexities involved in balancing exploitation and exploration. It is important to focus some attention on considering whether behavioural ambidexterity is predominately an organisational issue or an individual behavioural issue given that the extant literature sends mixed messages.

\section{Notes}

1. For the purpose of this article, this general description suffices. We acknowledge that there is a lot more to be said about the political climate in both countries, but such a discussion is outside the scope of this article.

2. The REF is the system for assessing the quality of research in UK HEls. For detailed information, please go to www.ref.ac.uk/.

3. For an in-depth discussion about the research methodology, methods and processes, please see (Ani Raiden and Christine Räisänen), Combining gendered strategies, a narrative approach and coaching to examine the effect of behavioural ambidexterity on individual well-being and high performance work, in Wheatley, D. (ed.), Handbook of Research Methods on the Quality of Working Lives (Edward Elgar, forthcoming).

\section{Disclosure statement}

No potential conflict of interest was reported by the authors. 


\section{Notes on contributors}

Ani Raiden is Senior Lecturer in Human Resource Management at Nottingham Business School. She teaches international human resource management, principles of management, and people resourcing on postgraduate courses in the Nottingham Business School. Ani's research interests generally are in the area of people resourcing and strategic HRM, specifically in connection with 'quality of working life'. Recently, her focus has been on work-life balance, gender and health and safety. Ani is a Chartered Member of the Chartered Institute of Personnel and Development (CIPD) and a Fellow of the Higher Education Academy.

Christine Räisänen is a linguist by training, and currently a full professor emerita at the Division of Construction Management at Chalmers University of Technology, Sweden. Her research builds on the sociology of work and philosophical considerations of space, place and aesthetic action. Christine runs courses on leadership and academic writing primarily for Master's and PhD students in Sweden and the UK.

Gail Kinman is a Chartered Psychologist and an Associate Fellow of the British Psychological Society, and a Fellow of the Higher Education Academy. She is the Director of the Research Centre for Applied Psychology at the University of Bedfordshire. Gail's research interests are in the area of occupational health psychology. Gail has a long-standing interest in the psychosocial working conditions of those who do emotionally demanding and knowledge-intensive work and the implications for their well-being, work-life balance and job performance. Another key interest is the ways in which working conditions influence sickness behaviours such as presenteeism. Gail has conducted research in these areas with various occupational groups, with a particular focus on 'helping' professionals such as those working in health and social care, prison officers and fire and rescue personnel, members of the clergy and knowledgeintensive workers such as academics.

\section{ORCID}

Ani Raiden (ID) http://orcid.org/0000-0001-7176-1139

\section{References}

Ahammad, M. F., S. M. Lee, M. Malul, and A. Shoham. 2015. "Behavioural Ambidexterity: The Impact of Incentive Schemes on Productivity, Motivation, and Performance of Employees in Commercial Banks." Human Resource Management 54 (1): 45-62. doi:10.1002/hrm.21668.

Ambos, T. C., K. Mäkelä, B. Birkinshaw, and P. D'Este. 2008. "When Does University Research Get Commercialized? Creating Ambidexterity in Research Institutions." Journal of Management Studies 45 (8): 1424-1447. doi:10.1111/ j.1467-6486.2008.00804.x.

Ashcraft, G., and A. Trethewey. 2004. "Developing Tension: An Agenda for Applied Research on the Organization of Irrationality." Journal of Applied Communication Research 32 (2): 171-181. doi:10.1080/14795752.2004.10058565.

Barry, J., E. Berg, and J. Chandler. 2006. "Academic Shape Shifting: Gender, Management and Identities in Sweden and England." Organization 13 (2): 275-298. doi:10.1177/1350508406061673.

Bentley, P. J., H. Coates, I. R. Thompson, L. Goedegebuure, and V. L. Meek. 2013. Academic Job Satisfaction from an International Perspective: Factors Associated with Satisfaction across 12 Countries. Dordrecht: Springer.

Birkinshaw, J., and K. Gupta. 2013. "Clarifying the Distinctive Contribution of Ambidexterity to the Field of Organization Studies." The Academy of Management Perspectives 27 (4): 287-298. doi:10.5465/amp.2012.0167.

Cech, E. A., and M. Blair-Loy. 2014. "Consequences of Flexibility Stigma among Academic Scientists and Engineers." Work and Occupations 41: 86-110. doi:10.1177/0730888413515497.

Chang, E., H. Chin, and J. Ye. 2014. “Organizational Work-Family Culture and Working Mothers' Affective Commitment: How Career Expectations Matter." Human Resource Management 53 (5): 683-700. doi:10.1002/ hrm.2014.53.issue-5.

Clarke, C., D. Knights, and C. Jarvis. 2012. "A Labour of Love? Academics in Business Schools." Scandinavian Journal of Management 28: 5-15. doi:10.1016/j.scaman.2011.12.003.

Edgar, F., A. Geare, M. Halhjem, K. Reese, and C. Thoresen. 2015. "Well-Being and Performance: Measurement Issues for HRM Research." The International Journal of Human Resource Management 26 (15): 1983-1994. doi:10.1080/ 09585192.2015.1041760.

Enders, J., and M. Kaulisch. 2006. "The Binding and Unbinding of Academic Careers." In The Formative Years of Scholars, edited by U. Teichler, 85-95. London: Portland Press.

Gatrell, C., S. Burnett, C. Cooper, and P. Sparrow. 2015. "The Price of Love: The Prioritisation of Child Care and Income Earning among UK Fathers." Families, Relationships and Societies 4 (2): 225-238. doi:10.1332/ $204674315 \times 14321355649771$. 
Gibson, C. B., and J. Birkinshaw. 2004. "The Antecedents, Consequences, and Mediating Role of Organizational Ambidexterity." Academy of Management Journal 47 (2): 209-226.

Gonzalez-Mulé, E., and B. Cockburn. 2016. "Worked to Death: The Relationships of Job Demands and Job Control with Mortality." Personnel Psychology. doi:10.1111/peps.12206.

Grant, A. M., M. K. Christianson, and R. H. Price. 2007. "Happiness, Health, or Relationships? Managerial Practices and Employee Well-Being Tradeoffs." Academy of Management Perspectives 21 (3): 51-63. doi:10.5465/amp.2007.26421238.

Gregory, A., and S. Milner. 2011. "What Is 'New' about Fatherhood? the Social Construction of Fatherhood in France and the UK." Men and Masculinities 14: 588-606. doi:10.1177/1097184X11412940.

Grimaldi, R., M. Kenney, D. S. Siegel, and M. Wright. 2011. "30 Years after Bayh-Dole: Reassessing Academic Entrepreneurship." Research Policy 40: 1045-1057. doi:10.1016/j.respol.2011.04.005.

Hearn, J. 1999. "A Crisis in Masculinity or New Agendas for Men?" In New Agendas for Women, edited by C. Short and S. Walby, 148-168. London: Macmillan.

Hofstede, G., G. J. Hofstede, and M. Minkov. 2010. Cultures and Organizations: Software of the Mind. 3rd ed. New York: McGraw-Hill.

Humphrey, S. E., J. D. Nahrgang, and F. P. Morgeson. 2007. "Integrating Motivational, Social and Contextual Work Design Features: A Meta-Analytic Summary and Theoretical Extension of the Work Design Literature." Journal of Applied Psychology 92 (5): 1332-1356. doi:10.1037/0021-9010.92.5.1332.

Jain, S., G. George, and M. Maltarich. 2009. "Academics or Entrepreneurs? Investigating Role Identity Modification of University Scientists Involved in Commercialization Activity." Research Policy 38 (6): 922-935. doi:10.1016/j. respol.2009.02.007.

Kelliher, C., and D. Anderson. 2008. "For Better or for Worse? an Analysis of How Flexible Working Practices Influence Employees' Perceptions of Job Quality." The International Journal of Human Resource Management 19 (3): $419-431$. doi:10.1080/09585190801895502.

Kinman, G. 2014. "Doing More with Less? Work and Wellbeing in Academics." Somatechnics 4 (2): $219-235$. doi:10.3366/soma.2014.0129.

Kinman, G. 2016. "Effort-Reward Imbalance and Over-Commitment in UK Academics: Implications for Health, Satisfaction and Retention." Journal of Higher Education Policy and Management 38 (5): 504-518. doi:10.1080/ $1360080 X .2016 .1181884$.

Kinman, G., and A. McDowall. 2017. "Work Life Balance, Health and Wellbeing in a Time of Austerity." In Work-Life Balance in the Recession and Beyond, edited by S. Lewis and N. Payne, 23-44. New York: Routledge.

Kinman, G., and F. Jones. 2008a. "Job-Related Efforts, Rewards and Over-Commitment: Predicting Strain in Academic Employees." International Journal of Stress Management 15 (4): 381-395. doi:10.1037/a0013213.

Kinman, G., and F. Jones. 2008b. "Effort-Reward Imbalance, Over-Commitment and Work-Life Conflict in UK Academics." Journal of Managerial Psychology 23 (3): 236-251. doi:10.1108/02683940810861365.

Litrico, J.-B., and M. D. Lee. 2008. "Balancing Exploration and Exploitation in Alternative Work Arrangements: A Multiple Case Study in the Professional and Management Services Industry." Journal of Organisational Behavior 29: 995-1020. doi:10.1002/job.553.

Lorenz, C. 2012. "If You're so Smart, Why are You under Surveillance? Universities, Neoliberalism, and New Public Management." Critical Inquiry 38 (3): 599-629. doi:10.1086/664553.

McDonald, P., and E. Jeanes. 2012. Men, Wage Work and Family. New York: Routledge.

Menzies, H., and J. Newson. 2008. "Time, Stress and Intellectual Engagement in Acidic Work: Exploring Gender Differences." Gender, Work \& Organization 15 (2): 504-522. doi:10.1111/j.1468-0432.2008.00415.x.

Michel, A. 2011. "Transcending Socialization: A Nine-Year Ethnography of the Body's Role in Organizational Control and Knowledge Workers' Transformation." Administrative Science Quarterly 56 (3): 325-368. doi:10.1177/ 0001839212437519.

Oldham, G. R., and J. R. Hackman. 2010. "Not What It Was and Not What It Will Be: The Future of Job Design Research." Journal of Organizational Behavior 31: 463-479. doi:10.1002/job.v31:2/3.

Patel, P. C., J. G. Messersmith, and D. P. Lepak. 2013. "Walking the Tightrope: An Assessment of the Relationship between High-Performance Work Systems and Organizational Ambidexterity." Academy of Management Journal 56 (5): 1420-1442. doi:10.5465/amj.2011.0255.

Polkinhorne, D. E. 1995. "Narrative Configuration in Qualitative Analysis." Qualitative Studies in Education 8: 5-23. doi:10.1080/0951839950080103.

Ranson, G. 2012. "Men, Paid Employment and Family Responsibilities: Conceptualizing the 'Working Father'." Gender, Work and Organization 19 (6): 741-761. doi:10.1111/j.1468-0432.2011.00549.x.

Rudman, L. A., and K. Mescher. 2013. "Penalizing Men Who Request a Family Leave: Is Flexibility Stigma a Femininity Stigma?" Journal of Social Issues 69 (2): 322-340. doi:10.1111/josi.2013.69.issue-2.

Semmer, N., N. Jacobhagen, L. Meier, and A. Elfering. 2007. "Occupational Stress Research: The Stress-As-Offense-ToSelf Perspective." In Occupational Health Psychology: European Perspectives on Research, Education and Practice, edited by S. Mclntyre and J. Houdmont, 41-58. Vol. 2. Nottingham: Nottingham University Press.

Simsek, Z. 2009. "Organizational Ambidexterity: Towards a Multilevel Understanding." Journal of Management Studies 46 (4): 597-624. doi:10.1111/joms.2009.46.issue-4. 
Swart, J., N. Turner, Y. van Rissenberg, and N. Kinnie. 2016. "Who Does What in Enabling Ambidexterity? Individual Actions and HRM Practices." The International Journal of Human Resource Management 1-28. doi:10.1080/ 09585192.2016.1254106.

Taras, V., P. Steel, and B. L. Kirkman. 2011. "Three Decades of Research on National Culture in the Workplace: Do the Differences Still Make a Difference?" Organisational Dynamics 40: 189-198. doi:10.1016/j.orgdyn.2011.04.006.

van de Voorde, K., J. Paauwe, and M. van Veldhoven. 2012. "Employee Well-Being and the HRM-organizational Performance Relationship: A Review of Quantitative Studies." International Journal of Management Reviews 14: 391-407. doi:10.1111/ijmr.2012.14.issue-4.

van der Lippe, T., A. Jager, and Y. Kops. 2006. "Combination Pressure: The Paid Work-Family Balance of Men and Women in European Countries." Acta sociologica 49 (3): 303-319. doi:10.1177/0001699306067711.

Vehviläinen, M., P. Vuolanto, and O.-H. Ylijoki. 2010. "Gender Equality in Interface Organizations between Science, Technology and Innovation." Journal of Technology Management \& Innovation 5 (1): 64-74. doi:10.4067/S071827242010000100005.

Wood, S., M. van Veldhoven, M. Croon, and L. M. de Menezes. 2012. "Enriched Job Design, High Involvement Management and Organizational Performance: The Mediating Roles of Job Satisfaction and Well-Being." Human Relations 65 (4): 419-446. doi:10.1177/0018726711432476.

Yli-Joki, O.-H. 2013. "Boundary-Work between Work and Life in the High Speed University." Studies in Higher Education 38 (2): 242-255. doi:10.1080/03075079.2011.577524. 